Article

\title{
Adaptation to the Impacts of Climate Extremes in Central Europe: A Case Study in a Rural Area in the Czech Republic
}

\author{
Robert Stojanov $^{1, *}$, Barbora Duží ${ }^{2}$, Tomáš Daněk ${ }^{3}$, Daniel Němec ${ }^{4}$ and \\ David Procházka ${ }^{5}$
}

1 Geographic Migration Centre, Department of Social Geography and Regional Development, Faculty of Science, Charles University in Prague, Albertov 6, 12843 Praha 2, Czech Republic Institute of Geonics of the Czech Academy of Sciences, Drobného 28, 60200 Brno, Czech Republic; E-Mail: arobrab@centrum.cz

3 Department of Development Studies, Faculty of Science, Palacky University Olomouc, 17. listopadu 12, 77146 Olomouc, Czech Republic; E-Mail: tomas.danek@upol.cz

4 Department of Economics, Faculty of Economics and Administration, Masaryk University, Lipová 41a, 60200 Brno, Czech Republic; E-Mail: nemecd@econ.muni.cz

5 Department of Informatics, Faculty of Business and Economics, Mendel University in Brno, Zemědělská 1, 61300 Brno, Czech Republic; E-Mail: david.prochazka@mendelu.cz

* Author to whom correspondence should be addressed; E-Mail: stojanov@centrum.cz; Tel.: +420-221-951-989.

Academic Editor: Rafael D’Almeida Martins

Received: 31 May 2015 / Accepted: 8 September 2015 / Published: 17 September 2015

\begin{abstract}
The primary objective of this paper is to analyse households' adaptation measures to the impacts of repeated extreme weather events, specifically floods, which belong amongst the most serious manifestation of ongoing climate change in Europe. The case study focuses on a rural area in the north-east part of the Czech Republic, in the catchment basin of the Bečva River. A total of 605 households were addressed within the framework of the questionnaire survey. On the basis of the conducted research, we determined that the total amount of adaptation measures adopted by those dwelling in residential homes within the investigated catchment area was relatively low. In contrast, however, one of the most important adaptation measures-house elevation-was applied by $46.94 \%$ of the houses (up to $1 \mathrm{~m}$ ) and by $21.16 \%$ houses (elevated more than $1 \mathrm{~m}$ ) respectively. We also found that the amount and scope of adaptation measures realized by households were influenced by certain socio-demographic factors of the inhabitants. The most statistically significant factors included households with more residents or families
\end{abstract}


with more children living in the household, as well as those with a higher level of education. Flood experience, the level of damage, and individual flood risk perception also played an important role.

Keywords: households; adaptation; climate extremes; floods; the Czech Republic; Bečva River; social inequality; risk management; flood risk perception

\section{Introduction}

Climate change represents a serious ongoing environmental transformation and international communities and individual nations make great efforts to cope with it [1,2]. Within the European framework, attention has been focused to date on alleviating the envisaged negative impacts of climate change on the functioning of natural and socio-economic systems. This includes the area of mitigation strategies (primarily a reduction in the amount of discharge of greenhouse gases), as well as a shift in emphasis towards the need for implementing preventive and adaptation strategies for climate changes already under way [3]. There is also significant innovative potential in the search for new adaptation management methods, such as "adaptive co-management for climate change adaptation" [4], the search for pathways for adaptation measures while taking into account the high level of uncertainty or a bottom-up approach to adaptation, known as "community-based adaptation" [5].

One serious manifestation of climate change is climatic variability, involving extreme fluctuations in the frequency, distribution, occurrence, and intensity of rainfall, temperatures, wind direction, etc.; in other words, climate extremes which cause related impacts in the form of floods, drought, water scarcity, fires, diseases, energy outages, etc. [1,6]. These impacts influence the quality of life of individuals, communities and entire societies. The adaptation methods to these changes depend on the resilience capacities of the community affected, i.e., the extent to which the given community is sensitive and vulnerable to these climate extremes, and the extent to which it is capable of adapting to them.

This paper focuses on the dynamics of extreme forms of rainfall which have a negative impact on the socio-economic sphere (human settlements, infrastructure, and various branches of the economy), primarily in the form of flooding. A higher frequency of flooding has been recorded over approximately the last two decades in the Czech Republic beginning in 1997. Catastrophic floods which exceeded national borders and impacted Central Europe occurred in 1997, 2002, 2010, and once again in 2013. Smaller, regionally confined floods with a shorter period of duration occurred, for example, in 2006 and 2009. Climatologists, due to the employment of more precise downscaling climatic models, also warn about an increasing trend in the frequency of river flooding in Europe in the future [7].

The article focuses more specifically on (i) an analysis of the extent and evidence of impacts of climate extremes, in particular floods in the target region; (ii) household adaptation measures with regard to occurrences of climate extremes; and (iii) drivers of adaptive decision-making and household behavior.

The primary aim of this work is to identify and analyze adaptation methods in the population to the impacts of climatic extremes, primarily flooding on households in the Bečva River basin in the 
Czech Republic. Household potential for adaptation has been greatly overlooked for several decades. The current paper should contribute to an improved recognition of potential capacity to adapt on the part of households. The results of the research should also support additional socio-economic and geographical research as well as the application of affordable adaptation measures in order to enable households to adapt in an improved fashion to climate extremes in the future.

The fundamental hypotheses were established as follows:

(i) households which face floods and flood damage more frequently (the experience factor) tend to adopt measures to protect their home and property; and (ii) certain socio-demographic and economic characteristics influence the decision-making of household members (their identification and characterization is the subject of the research).

\section{Adaptation to Climate Change}

\subsection{Conceptual Framework}

Change in the Earth's climatic system, primarily in the form of extreme climatic events, is generating extensive discussion in both academic and political circles. Hansen, Satoa, and Ruedy [8] point out, for example, the higher incidence of temperature anomalies over the course of the last thirty years in comparison with the average temperatures of the preceding decades. More detailed statistical analyses indicate that over the last decade, in particular, there have been an increased number of extreme weather events (e.g., Coucou and Rahmstorf [9]).

Substantial numbers of papers have been published on climate change adaptation, focusing on the situation in developing countries as well as on developed regions; an enumeration of them would exceed the capacity of this paper. The research subjects are extremely diverse, ranging from local adaptation strategies to climate variability in agriculture, such as crop diversification [10], adaptation to climate extremes in the food system in developing countries [11], community-based climate change adaptation in small developing island states [12], historical adaptation processes [13], an understanding of local time-based practices dealing with threats in a rise to the sea level [14], migration as a possible adaptive response to risks associated with climate change [15], and ending with conceptual papers devoted to the framing and conceptions of adaptation [16], the cultural and social dimensions of adaptation [17], the economy and the costs of adaptation [18], and managing adaptation measures from private and public resources [19]. This overview serves as a basic list which draws from broad climate change adaptation and we will develop the households' adaptation in more detail in the following chapter.

The increased occurrence of climate extremes has also been registered for a significant period of time within the observed territory. Within the context of Central Europe, Machar and Drobilová [20] state that based on current measurements, temperatures are increasing by an average of $0.5{ }^{\circ} \mathrm{C}$ over 10 years and a further increase is expected. The average temperature has increased by $0.3{ }^{\circ} \mathrm{C}$ over recent decades in the Czech Republic. Substantial inter-year and spatial variability needs to be taken into consideration, however. The same characteristics also apply to the frequency, distribution, and volume of rainfall. Their sum total is increasing slightly year by year, although there is considerable 
variability in their distribution over space and time. This leads to a higher frequency of occurrence of dry periods which alternate with storm rainfalls and subsequent flash floods [20].

The need to seek out optimal methods of adaptation for ongoing or projected changes in climatic conditions has been emphasized of late. According to Heffernan [21], adaptation as a strategy of coping with climate change, in contrast to mitigation strategies, has not remained at the center of scientific focus to date. Recently, however, the reality of climate extremes in the form of events, such as floods, droughts or heat waves [22], has forced researchers and policy-makers to explore ways of handling these extremes and adaptation to climate change has become more topical and pertinent than ever before.

Generally speaking, adaptation is seen as a common strategy amongst living organisms in adjusting to changing environmental conditions, including those related to climate. Climate change adaptation as a theoretical construct with practical measures is framed more specifically as "an adjustment in natural or human systems in response to actual or expected climate stimuli to their effects, which moderates harm or exploits beneficial opportunities” [23]. A number of regions face significant natural and societal changes due to a combination of increased economic and residential welfare in flood-prone areas and increased societal vulnerability and incapacity to manage climate extremes [24], climate change, and its impacts.

The IPCC [25] distinguishes between adaptation approaches which are planned (the result of deliberate policy decision based on an awareness of changing conditions, with the aim of achieving a desired state) and autonomous or spontaneous (adaptation that does not involve a conscious decision but is triggered by environmental change). Anticipatory (proactive) adaptation takes place before the impacts of climate change are observed and also corresponds with sustainability principles, based on a strong preventive and cautious approach.

In addition to the international/national/regional level, community-based adaptation to climate change (CBA) is regarded as a promising approach to adaptation. It aims at incorporating adaptation from the perspective of local communities. Reid and Huq [26] stress a bottom-up approach and define CBA as “a community-led process, based on communities' priorities, needs, knowledge, and capacities, which should empower people to plan for and cope with the impacts of climate change”. CBA is also mentioned as an effective adaptation method by the IPCC [1]. CBA has recently begun to be linked to ecosystem-based adaptation [27]. From this point of view, the connection between community needs, natural resources management and ecosystem services seems to be extremely promising and indicates a direction moving towards achieving genuine long-term and complex adaptation on regional levels. This area is under-researched in the Czech Republic, particularly from the perspective of economically disadvantaged rural regions.

Van Aalst et al. [28] have explored the value of using community risk assessments (CRA) for climate change adaptation which help address community engagement in climate risk reduction particularly in developing countries. On the basis of their experience, CRA is a valuable tool for climate change adaptation, specifically for informing bottom-up approaches to climate change adaptation. While community-based risk reduction is no panacea for all aspects of climate risk, CRAs do already contribute to adaptation to climate change and could play a larger role if employed more systematically. 
Based on the level and complexity of adaptation, one can differentiate between short-term (coping) strategies, residing in simple, short-term, and fairly reactive measures and genuine adaptation strategies (adaptation) which are focused on complex changes, the long-term effect, and an attempt to preventively avert adverse impacts [1].

As concerns focusing on a specific adaptation to a potential flood risk, Mechler and Kundzewicz [29] have differentiated between protection strategies, accommodation or retreat. A protection strategy is focused primarily on ensuring a high degree of protection of the population and infrastructure against flood risks, residing in the implementation of "hard" structural measures (barriers, dams, relief channels or retention reservoirs). Although these measures have contributed to reassuring the population and restoring their faith in protection against floods (e.g., Vaishar et al. [30]), the reality of flooding events has demonstrated that this strategy does not guarantee complete protection against the consequences of floods and only protects to a certain extent [31,32]. An accommodation strategy of floods or coexistence with floods represents the most commonly used strategy, which involves counting upon a certain degree of flood risk and seeks a combination of structural hard (technical) or soft measures akin to nature through a combination of preventive measures, including the rectification of damages and renewal. The last and relatively radical retreat strategy entails a withdrawal and a resettlement of the population or relocation of economic activities from risk areas to safer ones. This strategy is problematic from a number of perspectives: the flood territories of rivers have been built on to a large extent in the past, remain attractive for further economic development or settlement and people are relatively reluctant to abandon their place of residence.

Within this context, certain authors such as Vávra et al. [33] and Klijn et al. [34] point to a recent shift in public perception and water management practice from a narrow hydrological perspective to a broader framing which incorporates climate change risks into policies and legislation.

\subsection{Household Adaptation to Climate Change}

Preparedness, especially on a local or individual level, specifically the preparedness of households, remains outside the focus of interest. The number of research projects and papers dealing with household adaptation has recently increased. The primary inspiration comes from Great Britain (UK) where the PREPARE project was implemented from 2012 to 2013 [35]. The project focused on adaptation to floods as well as heat waves and other climate extremes. British researchers distinguish between household coping (short-term) and adaptation (long-term) measures. They pointed out that proactive adaptations involving personal, financial and technical investments were not commonly used; instead, they found that UK households struggled to build long-term adaptive capacity and were reliant upon traditional reactive coping responses. They identified past exposure to extreme weather, pressure of social acceptability, and long-term financial rewards as the main drivers of adaptation. Porter et al. [35] have expressed the view that new (state or private) initiatives are needed in order to encourage long-term household adaptation.

Another study from the UK [36] revealed a fairly low level of willingness to adopt certain flood-protection measures on the part of household residents. The majority held the view that the municipality is responsible for flood risk protection. Researchers have determined that younger respondents and those with a greater awareness of climate change expressed a greater willingness to 
implement household adaptation measures than others. This demonstrates that the perception of environmental risk plays an important role. The author recommended more effective flood risk communication, information support, and material support for the poorest part of the population. Lane et al. [37] similarly explored the rapid shift in the dominant technologies used to map flood risk in the United Kingdom and employed an experimental approach to public participation, tested in two different locations. Both revealed that the state of the socio-environmental context within which the events take place is as significant as the magnitude of the events themselves.

Further relevant observations have emerged from Germany based on household research by Kreibich et al. [24,38] focused in particular on building precautionary measures and construction adjustments. They remarked that households in Dresden which experienced flooding in 2002 adopted one or more precautionary measure after the flood and significantly improved their adaptations. Whereas only $17 \%$ of households were prepared in a certain way prior to 2002 , the number had increased to $67 \%$ by 2005 as a result of the flood experience and improved municipal flood risk management.

Kreibich [39] conducted further research in order to detect factors influencing motivation to adopt certain precautionary measures through a component analysis. Correlation and the principal component analysis reveal the slight influence of perception concerning the consequences of climate change on motivation to undertake flood emergency measures. Additional socio-economic factors, however, such as the socio-economic structure of households, including private ownership, and household size (the more people, the greater motivation) are far more important, similarly as with the case of flood experience. Based on this research, she argues that public awareness raising campaigns and schemes utilizing financial and non-financial incentives should be undertaken, directed towards household members.

Those specifically living in a detached dwelling are able to choose a construction solution which reduces or increases its potential resistance to the impact of climate extremes. The technical-architectural concept plays an important role in and of itself. Botzen et al. [40] have conducted, for example, an economically-focused study in the Netherlands, in which they determined respondents' willingness to pay for flood insurance in comparison with their willingness to pay for measures to reduce the flood risk in the form of constructing a raised ground floor to their house. The results demonstrated that approximately $52 \%$ of respondents gave priority to a raised ground floor, thereby wishing to actually resolve the problem rather than merely paying for insurance. The authors argue that approach is influenced by previous experience of affected population in the Netherlands where the number of flood events has increased markedly, and people are aware of the risks to a greater extent. It should be stated, however, that only "willingness" was investigated and not actual measures.

Schelfaut et al. [41] have specified three dimensions of resilience-relevant measures (an interplay of institutions, flood risk communication and flood modeling tools) and reviewed them with three case studies in Flanders (Belgium), Niedersachsen (Germany), and Calabria (Italy) as part of the FREEMAN project (flood resilience enhancement and management). They concluded that the participation of all stakeholders and bottom-up involvements are considered important factors. Furthermore, techniques to increase participation will increase the ownership of solutions and increase resilience. Increasing the strength of a community is also about increasing the strength and scope of the internal connections between its individuals, organizations, and the physical environment which forms that community. 
Each nation or region has, of course, its own specific traditions in terms of house construction, demographics, along with its own social and economic situation. It is consequently of importance to conduct case study-oriented research in order to determine both regional and other specifics and differences and provide new observations and local experience. Although a substantial number of papers deal with climate change adaptation in Western Europe there are, therefore, not many studies focusing on Central and Eastern European countries, and for this reason this paper attempts to contribute to the scant literature on the topic.

It is argued that households represent an important economic and social unit with its behavior and decision-making playing an important role in climate change adaptation. The household strategy is also influenced by how its members perceive the environmental risk of their place of residence or the impact of their activities, or the resources they have available to improve the situation. As outlined for example by Vaishar [30], with regard to the issue of flooding, people often do not take responsibility for the fact that they live in a flood region and have a tendency to shift the responsibility for flood protection onto regional or state authorities.

Those specifically living in a detached residence are able to choose a construction solution which reduces or increases its potential resistance to the impact of climate extremes. The technical-architectural concept plays an important role in and of itself. Research into construction measures aimed at reducing the flood risk to a certain extent and improving the management of storm rainfall has been conducted, for example, by Kreibich et al. [24,38] who employ the term precautionary measures. They are part of a small group of authors who describe these measures in a relatively detailed manner based on the economic costs needed for investment. The low-cost measures include the gathering of information related to precautionary measures, the assistance of neighbors, and the relocation of risk objects from the ground floor to safer locations. Medium investments include insurance against floods, adaptations to the interior (e.g., floor replacement), and securing of flood embankments and barriers. High-cost measures include rebuilding the heating system (in order to prevent the risk of its flooding, for example by relocating the boiler from the basement to a higher floor, purchase of a mobile (demountable) boiler, removal of underfloor heating on the ground floor, etc.). The highest investments involve construction adjustments to the building using solid and water-resistant materials, a raised ground floor, sealing in important parts of the house, fortification of the cellar and foundations of the building and construction of small anti-flood walls on the surrounding lands.

Within the Czech environment, limited research has been conducted on the theme of the impacts of climate extremes and the selection of adaptation measures on the part of households. There are only a few exceptions, for example Duží et al. [42,43], in selected communities within the region in question, or Vaishar et al. [30], who focused on a description of several regional case studies on the management of the flood events after 1997 in the Czech Republic and who outlined a progressive method for dealing with this issue, combining a sociological and physical-geographical analysis. The issue of flooding, its historical trend, and comparison has been the subject of studies focused on the catchment basin of the largest rivers, the Morava and Labe [44,45]. It is possible from a historically-based observation to identify a trend involving a slightly increasing number of floods, as well as other extremes, primarily drought. Studies from the region on the theme of adaptive measures have focused to date on studying the influence of floods on commuting to work [46]. 


\subsection{Household Adaptations in the Czech Republic-Research Design}

The following conceptual framework (Figure 1) describes the research design of the paper in detail. Figure 1 shows the household as the fundamental unit of research and the scope of potential adaptive behavior. The work of Kreibich et al. [24,38] focused on adaptation theory is the basis, specifically household adaptation, along with our own research experience and knowledge. We consequently conducted field observation of house construction practice in the Czech Republic and created our own conceptual framework on the basis of this knowledge and information. This framework thereby incorporates the suggested range of realistic household strategies suitable for the Czech Republic.

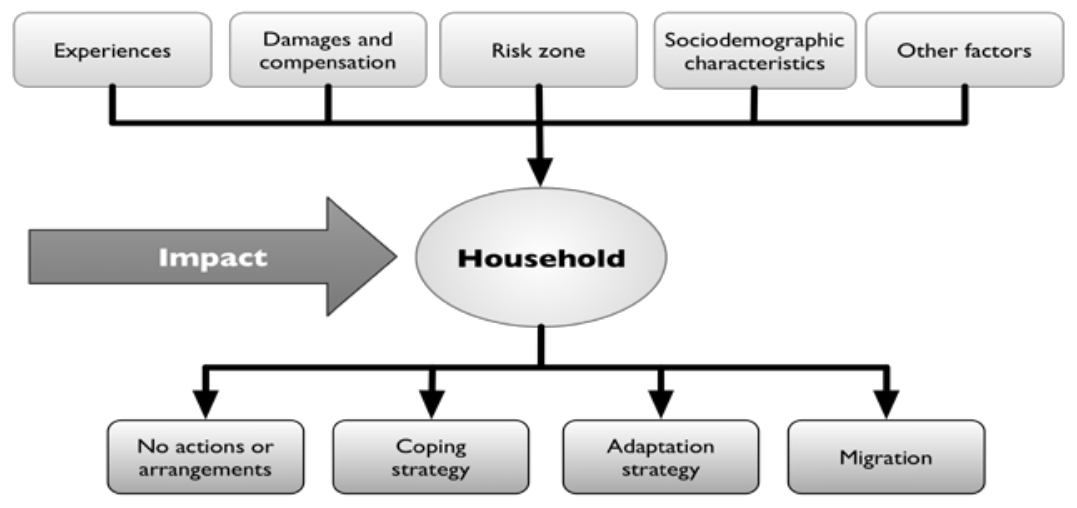

Figure 1. Conceptual framework of potential models for household adaptation strategies. Source: own processing.

The household strategy may begin with no steps or "resignation" concerning the measures. This is followed by simple, cheap, intuitive, short-term measures (coping strategy), corresponding more with minor adjustments within the interior of the house. More thorough, anticipatory, and financially costly adaptation measures are focused on the building construction of the house, primarily a raised ground floor or the protection of the house against dampness, along with terrain and other adjustments of the surrounding plot (adaptation strategy). The last opportunity consists of the migration strategy which is usually the most complex household adaptation strategy in developed countries. This concerns migration in the case of a significant change to the environment, the loss of a dwelling as a consequence of an extreme natural or anthropogenic event, or the loss of subsistence [47]. This would represent migration as a response to repeated floods or other climate change impacts in the present case.

After determining the potential drivers which influence adaptation, Grothmann and Reusswig [48], Kreibich [39], and other studies dealing with household adaptation were greatly inspirational. The most relevant variables were presented and new ones were added in order to obtain a complete view of the issue and cover the entire range of options. Quantitative variables were initially suggested, such as the number of flood experiences and household location in the risk zone, the level of damage and the share of compensation. Socio-demographic and economic characteristics (age, number of residents, family size, level of education, employment, etc.) cover information concerning key respondents as well as other household members. They also provide a suitable background for research and detecting key factors. Flood risk perception was also established as a dummy variable. All these variables served 
in descriptive statistics as well as regression models which allowed us to create a complete picture of the household in the target region.

\section{Methodology and Data}

\subsection{Characteristics of the Researched Territory}

This study focuses on extreme natural occurrences, primarily the incidence of floods, the main causes of which have included persistent or intensive storm rainfall in the summer season, as well as spring floods as a consequence of a rapid rise in temperatures and a thawing of snow. The study focuses on the time period following 1997 when the Czech Republic was hit by the largest floods in its modern history up until 2012 when the collection of data was commenced.

The Bečva River is the longest left-sided tributary of the Morava River and has an entire range of its own tributaries (see Map 1). Approximately 655 water surfaces are connected to the river. The Bečva, together with its tributaries, is $120.2 \mathrm{~km}$ long, the area of its catchment basin measures 1627 $\mathrm{km}^{2}$ and the average annual flow of water at the confluence with the Morava River is $18 \mathrm{~m}^{3} \cdot \mathrm{s}^{-1}$ which is highly uneven over the course of the year [49].

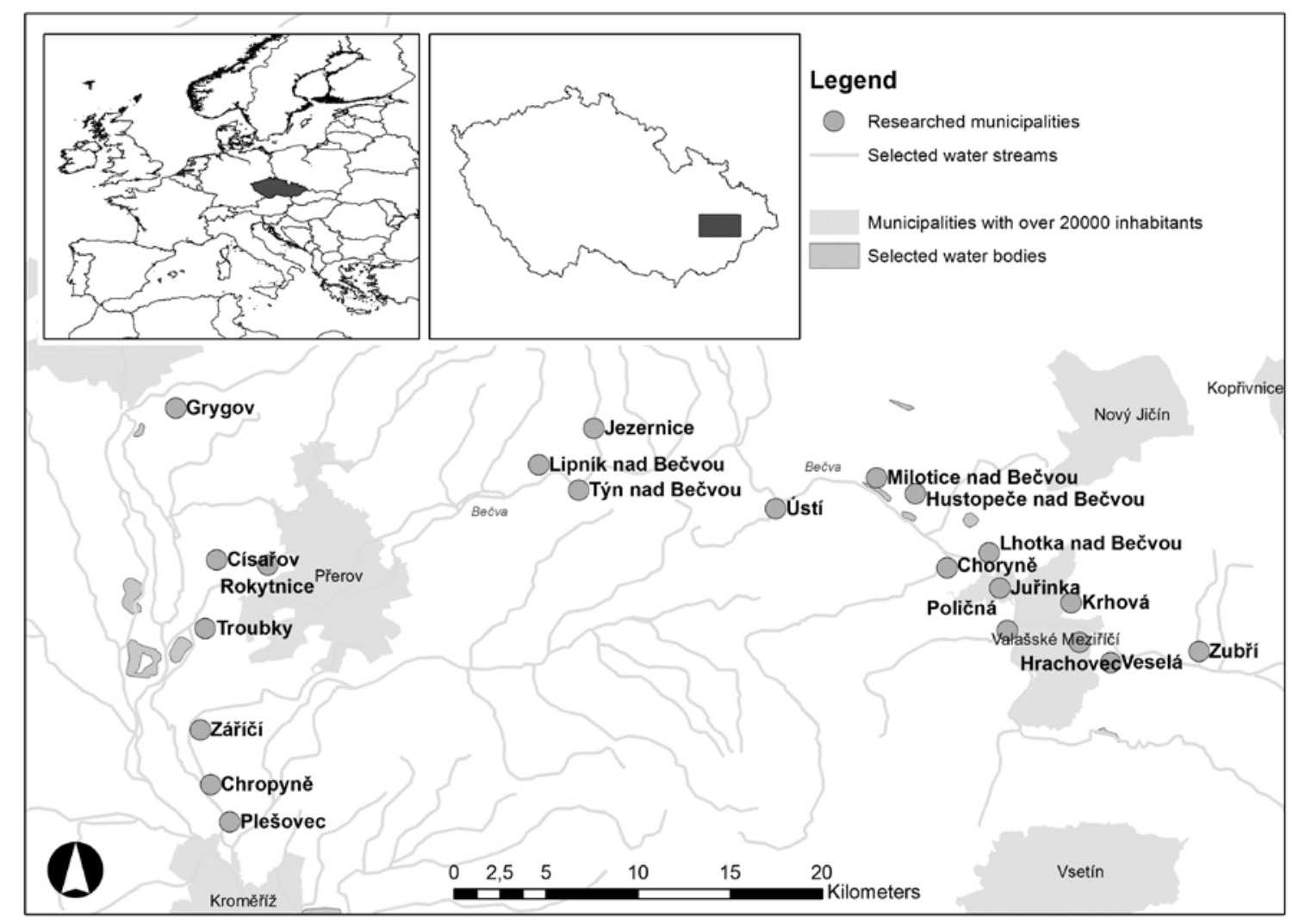

Map 1. Area of research (source: authors).

Smaller municipalities of a rural character and, if applicable smaller towns or integrated units, thereof, were selected for the field investigation. The upper reaches of the Bečva River basin is distinguished by more of a precipitous character, with uneven through flows and a high outflow rate, including a considerable erosion of gravel into the plain where it accumulates. The area has the 
character of a forested agricultural landscape. The lower retention capacity of the landscape is due to the flysch substratum in the mountainous regions (characteristic of the predominant part of the Western Carpathians) and the higher incline of the mountain slopes. Heavily fluctuating rainfalls over the course of the year, including a higher feed of rainfalls from the mountain range of the Moravian-Silesian Beskydy [50] contribute to the fact that the instability of the outflow rate of the Bečva River is evaluated as amongst the largest in the Czech Republic and large differences are manifested between the values of the minimal through flows and the contrastingly culminating through flows of flood waves. Lowland regions predominate in the lower flow of the river with an average height of $200 \mathrm{~m}$ above sea level and an intensively farmed landscape is predominant. The river takes on an overall calmer character with gravel-bearing activity entirely predominating. The character of any applicable flood also differs. Unlike the rapid onset and receding of floods in higher areas of the catchment basin, the flood water from the channel of the water flows has a tendency to persist in the floodplain for several days.

The Bečva River, including its tributaries, has been regulated and aligned to varying degrees since the end of the 19th century (approx. from 1897 to 1932). One of the main reasons for the regulation was the fear of repeating floods and an increased demand of local settlement and farming activity on the floodplain of the river. These adjustments have had, however, an entire range of negative consequences. The channel of the river has been narrowed, with an acceleration of the outflow rate, a deepening of the bed of the actual flow, an increase in the erosion activity of the river, and also a change in the character of the area surrounding the river [8].

Floods, along with wind-related storms, are considered the major natural hazard in the EU in terms of risk to people and assets [51]. The case study region was chosen on the basis of repeated floods as extreme climatic impacts over recent decades, having not been affected with such frequency and intensity of flooding previously. The repetition of the flooding also enabled a comparison of the individual events and a mapping of longer-term trends. Smaller municipalities were chosen due to the rural and demographic character of the river basin. Our objective was to identify household adaptation strategies specifically in rural areas where relatively little information exists, not only in specialized literature but also in the news media. An additional reason involved the need for comparable conditions for coping with the impacts of floods for all of the selected units of settlement (such as population, social and economic conditions and lifestyle). A selection of larger cities would not have been able to secure these comparable conditions within the given territory.

\subsection{Methodology of the Empirical Investigation}

A “door-to-door" questionnaire was chosen as the primary research method as this was viewed as one of the most useful instruments for obtaining relevant data (see QUESTIONNAIRE SURVEY in Supplementary Materials). The team also worked personally within the target area conducting field research and additional interviews with both stakeholders and experts, compiling photo documentation, etc. The information is consequently more thorough in comparison with a telephone or online survey or a desktop analysis.

The questionnaire investigation of selected households took into account a number of fundamental conditions: the respondents live in a house where they have their permanent residence and have lived 
there for at least five years. The basic circuits of the questionnaire were processed on the basis of a previous study and above all with the regional specifics of the region of the catchment basin of the Bečva using a combination of closed and open questions. Households were selected as the fundamental researched unit. As a rule, adaptation to climate change was addressed on a national or regional level; the individual level was not viewed as of equal importance. In the final result, however, households actually bear the consequences of manifestations of climate change. Their potential to adapt is greatly overlooked and was consequently chosen as the fundamental unit of research by means of a questionnaire investigation.

Questionnaire interviewing of the members of the household was conducted in 22 small municipalities selected in advance. The municipalities were chosen on the basis of a preliminary differentiation of the flood risk into zones of high, low and no-risk, corresponding to the probability of flooding of the region in question within a certain time frame: Q 20 (high-risk, corresponding to a probability of flooding once per 20 years), Q100 (low-risk, corresponding to a probability of flooding once per 100 years) and no-risk (longer time dispersion, higher location above sea level, further from a water source). The flood territories for 20 and 100 year frequency of flooding were taken from the DIBAVOD database [49]. This data was provided by the T.G. Masaryk Water Research Institute. The data on the water surfaces and water flows, similarly to the boundaries and positions of the individual municipalities, is taken from the Arc ̌́R database which was created by ARCDATA PRAHA, the Czech State Administration of Land Surveying and Cadastre [52].

The division of each of the municipalities into three risk zones was applied in the research into the households where based on possibilities one third of the households were addressed in each municipality in the high, low and no-risk zones (see Map 2). The resulting sample oscillated around 30 questionnaires per municipality, with this depending on the distribution of the risk zones, the size of the municipality, the willingness of the respondents to provide information and other factors. In light of the fact that households were not only threatened by the Bečva River but also by its tributaries, for which maps of the flood risk are not processed, the risk zones on the tributaries of the Bečva River were determined over the course of the research based on the experiences of the households stated by the respondents in the questionnaire investigation.

The sampling strategy was adapted in accordance with the research design and the geographical and sociological criteria were combined. The research was also supported by means of preliminary field research, discussion with local stakeholders, in particular mayors and experts. Several methods of sampling such as stratification were further combined in which we first created three risk zones in advance and aimed to cover each zone separately. Households located in each zone were consequently selected according to local maps or the current situation. Occasional opportunistic sampling was also added based on new information obtained during field research and interviews with local stakeholders, who recommended a household or even a specific address. 

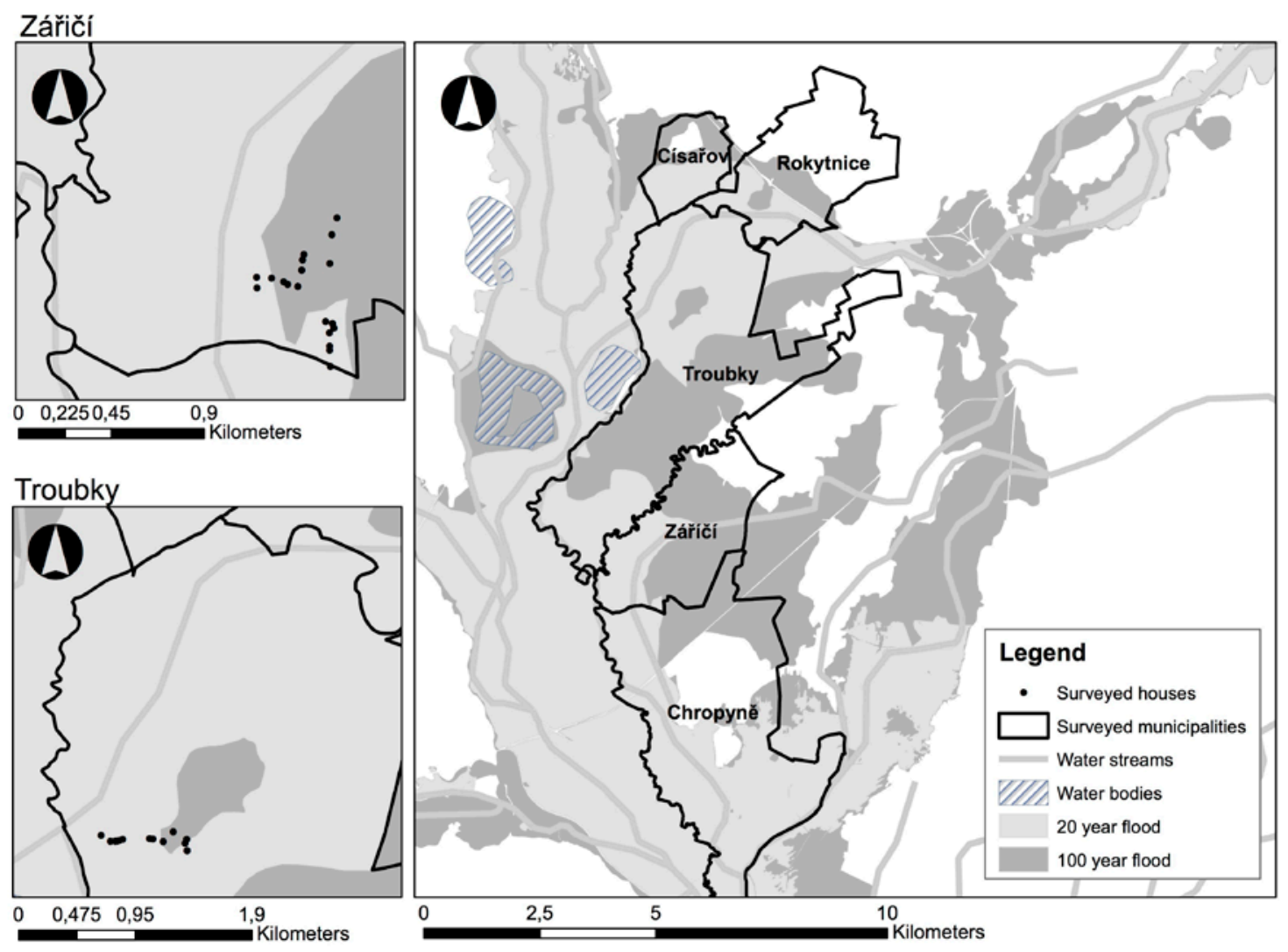

Map 2. Distribution of risk zones in individual municipalities using the example of the municipalities of Záŕíćí and Troubky (source: authors).

The questionnaire investigation was conducted evenly within the catchment basin of the Bečva River which could be characterized as the upper and medium reaches of the river. In total 605 usable questionnaires were obtained in total between the period of autumn 2012-summer 2013 from 22 municipalities of the region in question. The questionnaires were completed by the door-to-door method, which means that the researcher asked a member of the household "at the door" of the house, where the respondent completed the questionnaire. This ensured the possibility of explaining those questions which were not clear to respondents or of obtaining additional responses, personal opinions, and other information of interest in connection with each specific response. The respondents were guaranteed anonymity and were not asked about the names of the members of the household.

Across all risk zones, an estimated 200 households did not answer their door. Additionally, approximately 80 households answered, but then declined to participate. We achieve nearly $70 \%$ questionnaire return of all addressed household.

\section{Findings}

\subsection{Experience and Impact of Flood Events on Households}

The number of direct experiences with floods in the researched region is illustrated by Table 1 . From the perspective of zoning of the researched regions, an absence of experience with flooding corresponds to a no-risk area, one experience corresponds to a low-risk area, and multiple experiences correspond to a high-risk area. The number of flood events was determined by the answers of the 
respondents. In this particular case, we have related their experiences to the risk zones defined by the flood maps. Out of the total number of households, no flood was stated by 162 households (26.8\%), one flood by 268 households (44.3\%), and two or more floods by 172 households (28.4\%) over the period 1997-2012.

Table 1. Number of experiences with flood events.

\begin{tabular}{ccc}
\hline Flood Events & Households & Proportion (in \%) \\
\hline $\mathbf{0}$ & 162 & 26.8 \\
$\mathbf{1}$ & 268 & 44.3 \\
$\mathbf{2}$ & 141 & 23.3 \\
$\mathbf{3}$ & 21 & 3.5 \\
$>\mathbf{3}$ & 10 & 1.6 \\
no answer & 3 & 0.5 \\
Total & $\mathbf{6 0 5}$ & $\mathbf{1 0 0}$ \\
\hline
\end{tabular}

Table 2 further illustrates the frequency of flooding in individual years in connection with the estimated material damages, as stated by the respondents. The table makes apparent that the highest percentage of those affected by flooding was in 1997-a total of 384 households (62\% of the registered flood events). The second highest flood occurrence was in 2010 with two flood events in which 115 households were affected (19\%), followed by 2009, in which 48 households (8\%) expressed an experience with flooding.

The year 1997 also brought the most serious damages to the property of the affected population in the researched municipalities (71 million CZK), although the financial enumeration has to be approached with a certain degree of caution and the losses were calculated with higher degree of probability [53]. Further extensive damages were caused by the floods of 2006 (3.1 million CZK) and 2010 (9.3 million CZK). All losses are expressed in nominal values. Due to price level changes, the total real losses have been expressed in the prices of the year 2014 using the year-to-year consumer price indexes provided by the Czech Statistical Office. This allows us to compare the real losses across years and express the level of damages in relation to the prices of the year 2014. Despite the fact that floods also occurred outside of the years indicated in Table 2, the damages to 17 households from the floods in these years 2000-2001, 2007-2008, and 2011-2012 reached a sum total of 725 thousand CZK.

Table 2. Number of households influenced by floods and estimated damages (1997-2012).

\begin{tabular}{cccc}
\hline Year & Households & $\begin{array}{c}\text { Total Nominal Losses } \\
\text { (in 1000 CZK) }\end{array}$ & $\begin{array}{c}\text { Total Real Losses in Prices of } \\
\text { 2014 (in 1000 CZK) }\end{array}$ \\
\hline $\mathbf{1 9 9 7}$ & 384 & 70,900 & 114,502 \\
$\mathbf{2 0 0 2}$ & 36 & 1175 & 1516 \\
$\mathbf{2 0 0 6}$ & 20 & 3125 & 3752 \\
$\mathbf{2 0 0 9}$ & 48 & 2350 & 2556 \\
$\mathbf{2 0 1 0}$ & 115 & 9275 & 9939 \\
other & 17 & 725 & NA \\
\hline
\end{tabular}




\subsection{Construction of New Houses and Insurance}

The fundamental characteristics of buildings were determined amongst other factors within the framework of the questionnaire investigation. The respondents were asked about the year of construction of the house and about the height of its residential ground floor. The results demonstrated that almost one half of the houses (46.94\%-i.e., 284 houses) had a raised residential ground floor at a maximum height of up to $1 \mathrm{~m}$ and approximately $21.16 \%$ of the houses (128 houses) had a ground floor at a height of over $1 \mathrm{~m}$, this being the best variant in terms of averting flood risk.

The graph in Figure 2 demonstrates that the average percentage of houses with a raised ground floor has fallen over the last $40-50$ years from approximately $85 \%$ to almost $70 \%$. With regard to the higher occurrence of floods over the course of the researched approximately 15 years, this finding is surprising despite the brief increase in the number of such houses following the floods of 1997 (see Table 3).

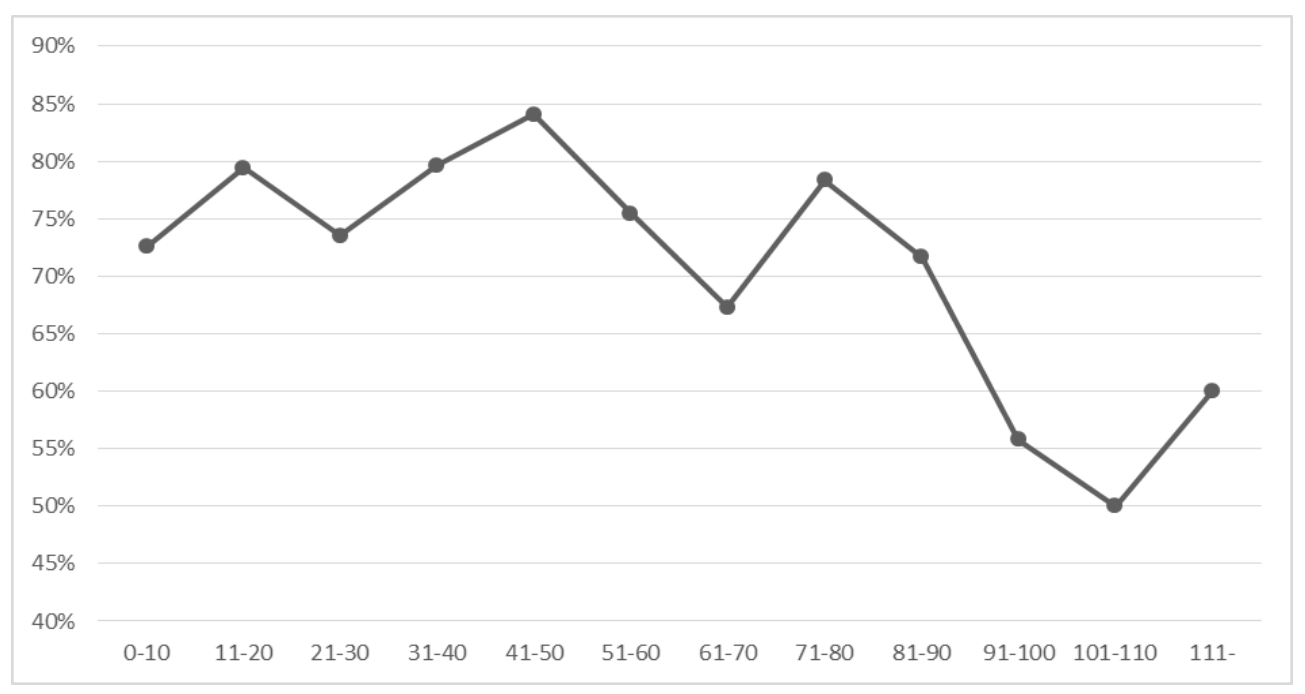

Figure 2. Relationship between the age of houses and the percentage representation of houses with a raised ground floor above a height of $1 \mathrm{~m}$.

Table 3. Ratio of new houses built in corresponding periods (in \%).

\begin{tabular}{|c|c|c|c|c|c|c|c|c|}
\hline \multicolumn{3}{|c|}{$\begin{array}{c}\text { Ratio to Houses Built } \\
\text { in Corresponding Periods }\end{array}$} & \multicolumn{6}{|c|}{$\begin{array}{c}\text { Ratio to Houses built in Corresponding Periods } \\
\text { (Relative to All Houses Built in Appropriate Risk Zone) }\end{array}$} \\
\hline \multirow{2}{*}{$\begin{array}{c}\text { House } \\
\text { Build Year }\end{array}$} & \multirow{2}{*}{$\begin{array}{c}\text { House } \\
\text { Level High }\end{array}$} & \multirow{2}{*}{$\begin{array}{c}\text { House } \\
\text { Level Low }\end{array}$} & \multicolumn{3}{|c|}{ House Level High } & \multicolumn{3}{|c|}{ House Level Low } \\
\hline & & & No-risk & Low-risk & High-risk & No-risk & Low-risk & High-risk \\
\hline $\begin{array}{c}\text { prior } 1997 \\
\text { (including } \\
1997 \text { ) } \\
\end{array}$ & 70.26 & 29.74 & 68.84 & 65.35 & 80.00 & 31.16 & 34.65 & 20.00 \\
\hline 1998-2008 & 81.08 & 18.92 & 100.00 & 84.62 & 61.54 & 0.00 & 15.38 & 38.46 \\
\hline $2009-2013$ & 68.18 & 31.82 & 50.00 & 72.22 & 75.00 & 50.00 & 27.78 & 25.00 \\
\hline
\end{tabular}

As can be seen from the graph in Figure 2 and Table 3 (the source data was provided by the respondents) there was, once again, a decline in the proportion of construction of new houses with a raised ground floor to $68 \%$ in the period following the floods in 2008. This decline was in all 
probability caused by the fact that the households gradually forgot about the floods of the past and returned in terms of their mindset to a status in which they relied on a lower probability of outbreak of intensive flooding.

The development in the number and proportion of houses with a raised ground floor differs with regard to the risk zone in which the house was constructed. It is of interest in this respect that in comparison with the status from the period prior to 1997, it is evident that even houses with the lowest risk of occurrence of flood were built with a raised ground floor (this was the case of $100 \%$ of the newly constructed houses in this zone and period in the current sample). People over this period and within the given territory in all probability perceived the danger of flooding extremely intensively. There was an evening out of the ratios, however, after the year 2009 and the proportion of houses with a raised ground floor within the zone with the lowest risk is the same as the proportion of houses without a raised ground floor.

The intensity of the floods of 1997 led to a situation in which there was an increase in the proportion of houses built with a raised ground floor in essentially all risk zones. As can be seen from Table 4, the total number of houses with a raised ground floor built in the interim period of 1998-2013 was 60, whereas the number of houses without a raised ground floor was only 21.

Table 4. Absolute numbers of new houses built over the period 1997-2013.

\begin{tabular}{ccccccccc}
\hline House & House & House & \multicolumn{3}{c}{ House Level High } & \multicolumn{3}{c}{ House Level Low } \\
\cline { 5 - 9 } Build Year & Level High & Level Low & No Risk & Low Risk & High Risk & No Risk & Low Risk & High Risk \\
\hline $\begin{array}{c}\text { prior 1997 } \\
\text { (including 1997) }\end{array}$ & 352 & 149 & 95 & 149 & 108 & 43 & 79 & 27 \\
\hline $\begin{array}{c}1998-2008 \\
2009-2013\end{array}$ & 30 & 7 & 11 & 11 & 8 & 0 & 2 & 5 \\
\hline
\end{tabular}

One of the fundamental parameters from the perspective of adaptation to the floods was insurance and damage compensation. A change was determined in the frequency of insurance, as well as in its amount and scope (only real estate, interior furnishings of homes, entire lands, farm buildings, etc.). Figure 3 indicates that the affected households, for reasons unknown to us, were quite often paid nothing or were paid damages up to the amount of $40 \%-50 \%$. Above this value, however, the amount of insurance benefits drops substantially, which means a large financial burden for even insured households.

During the course of the questioning, the respondents were also invited to comment upon the development within the area of insurance, in which the majority stated that insurance had become more expensive and that there had been a dramatic increase in the insured sum (most often after 1997 and 2010) to approximately two to three times its original level. 


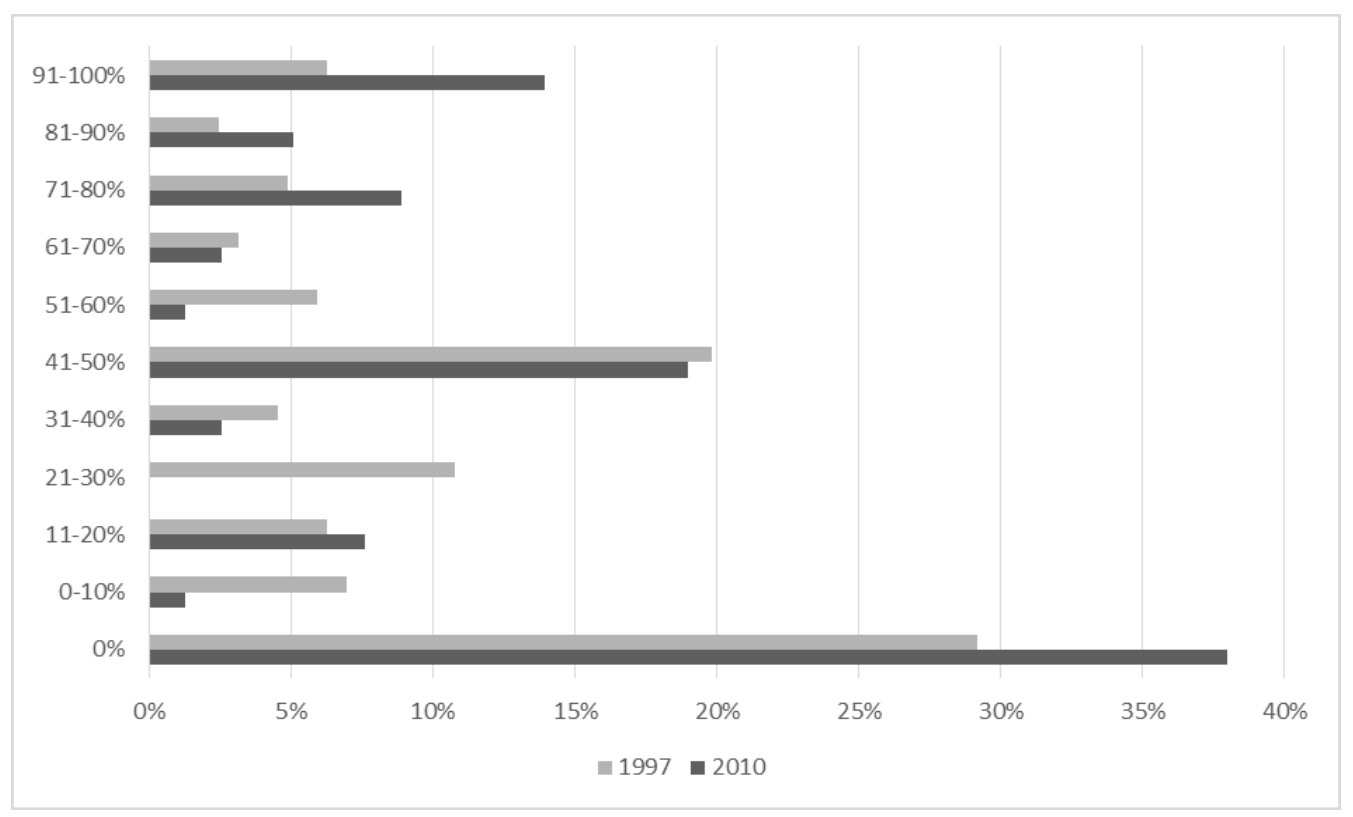

Figure 3. Insurance Compensation (ratio to all households with appropriate damage compensation).

\subsection{Adaptation Measures at the Level of Households}

As is apparent from Table 5, the largest number of interior adaptation (coping) measures was implemented following the floods of 1997. A further trend reveals a falling tendency with the exception of the relatively least demanding type of measures; namely, the acquisition or construction of mobile barriers. This trend is logical with regards to the amount of floods and the damages they caused. The households should be better prepared in subsequent periods.

Table 6 further illustrates the situation in the case of adaptation measures taken on the exterior. This table clearly indicates that a certain percentage of households had already adopted certain adaptation measures before the largest floods of 1997. In subsequent years the number of implemented adaptation measures was only minimal which can be seen from the fact that between 1997 and 2005 the inhabitants of the researched region were not confronted by any larger flooding and the situation did not change markedly even after the floods of 2010.

Table 5. Household coping measures-interior measures.

\begin{tabular}{cccc}
\hline Time Period & $\begin{array}{c}\text { Moving Possessions to } \\
\text { Higher Stories }\end{array}$ & $\begin{array}{c}\text { Changing } \\
\text { Floor Material }\end{array}$ & $\begin{array}{c}\text { Using Mobile Window } \\
\text { and Door Flood Barriers }\end{array}$ \\
\hline Before the 1997 flood & 50 & 42 & 19 \\
1997-2006 & 61 & 56 & 17 \\
2007-2010 & 16 & 1 & 13 \\
After the 2010 flood & 16 & 9 & 15 \\
Total & 143 & 108 & 64 \\
\hline
\end{tabular}


Table 6. Household adaptation measures — exterior measures.

\begin{tabular}{ccccc}
\hline $\begin{array}{c}\text { Time Period } \\
\text { and Risk Area }\end{array}$ & $\begin{array}{c}\text { Hydro-Insulation of } \\
\text { Houses and Walls }\end{array}$ & $\begin{array}{c}\text { Hydro-Insulation } \\
\text { through Drainage } \\
\text { around Houses }\end{array}$ & $\begin{array}{c}\text { Water } \\
\text { Management } \\
\text { of Plots }\end{array}$ & $\begin{array}{c}\text { Terrain and } \\
\text { Vegetation } \\
\text { Adjustments }\end{array}$ \\
\hline $\begin{array}{c}\text { No-risk } \\
\text { Before the 1997 flood }\end{array}$ & 9 & 31 & 12 & 4 \\
1997-2006 & 8 & 22 & 6 & 1 \\
2007-2010 & 1 & 3 & 4 & 2 \\
After the 2010 flood & 0 & 4 & 1 & 0 \\
Low-risk & 58 & 2 & 1 & 1 \\
Before the 1997 flood & 27 & 75 & 23 & 25 \\
1997-2006 & 27 & 43 & 7 & 7 \\
2007-2010 & 2 & 28 & 15 & 17 \\
After the 2010 flood & 2 & 4 & 0 & 0 \\
High-risk & 45 & 0 & 1 & 1 \\
Before the 1997 flood & 27 & 73 & 29 & 22 \\
1997-2006 & 7 & 32 & 13 & 8 \\
2007-2010 & 4 & 24 & 9 & 6 \\
After the 2010 flood & 7 & 1 & 1 & 0 \\
\hline
\end{tabular}

As regards the number of exterior measures per household, no adaptation measures were implemented in 58 households, $24.3 \%$ of people implemented only one type of measure, $12.2 \%$ of households implemented two types, and only $5.5 \%$ of households adopted three or more types of adaptation measures.

The relationship between the construction of a house with a raised ground floor and other adaptation measures is an interesting finding. If a house has a raised ground floor, the probability of any further measure being taken decreases by approximately $10 \%$. This is in all probability caused by the fact that life on a raised ground floor may appear safer to the inhabitants who do not view the taking of further measures as necessary. This conclusion is based on a view of the relative frequency of the representation of individual types of houses and adaptation measures, in which $28.4 \%$ of houses with a raised ground floor adopted an adaptation measure (117 of 412 houses) as opposed to 37.6\% of houses without a raised ground floor (60 of 170 houses) [54].

Figure 4 illustrates the interesting information that the largest number of adaptation measures were implemented throughout the entire researched period in the low-risk zone, whereas it would be expected that this would be the case in areas with the highest risk.

This cannot be explained by the fact that households located in the high-risk zone were already prepared, since this concerns data for the period 1997-2012 and before this period no floods had been recorded for a significant period of time. The aforementioned values can, in all probability, be explained by means of the perception of the members of certain households living in low-risk zones who perceived the potential risks of flooding and other natural disasters more seriously than the inhabitants of the highest risk zones who were, in contrast, used to these risks and, as a result, did not take them as seriously. They consequently immediately implemented a number of measures on their home/land. Economic factors could also have played a certain role. 


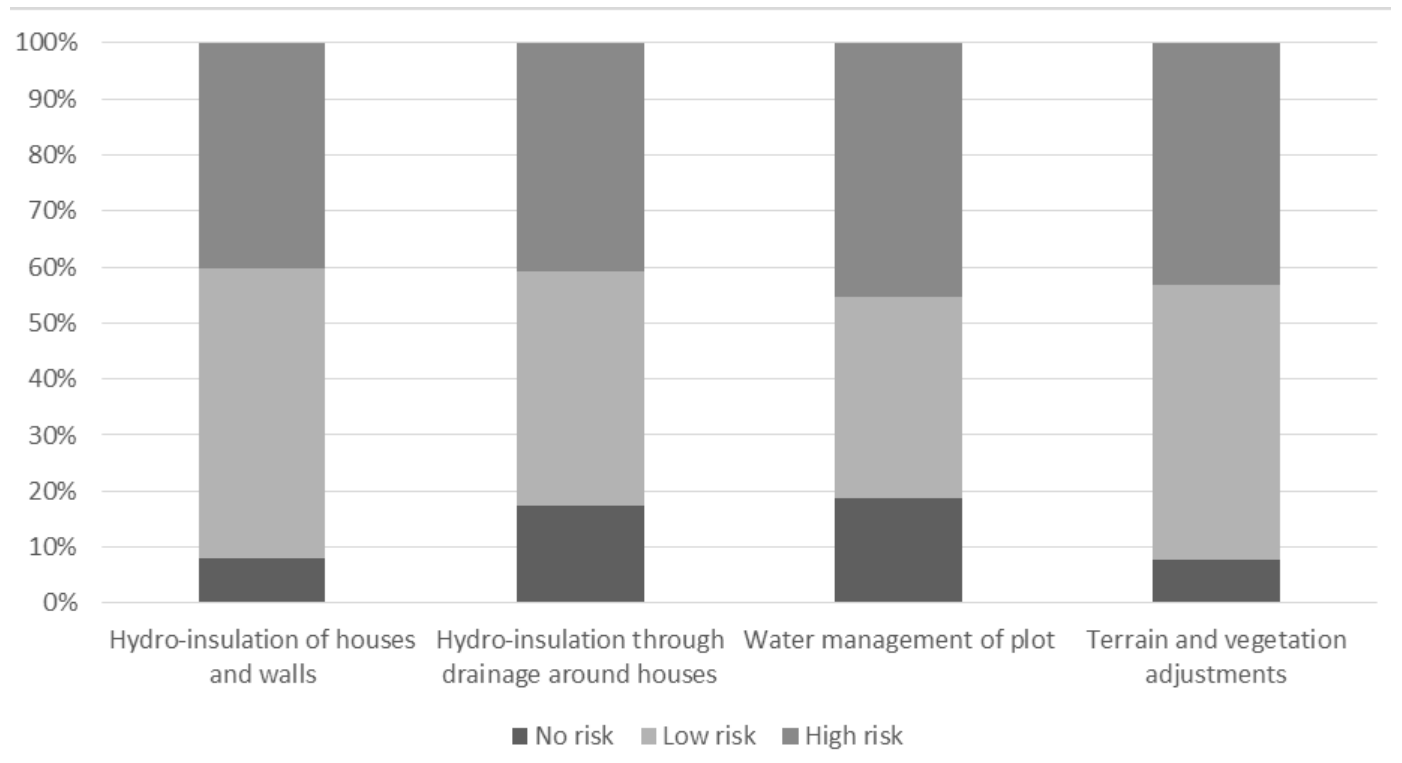

Figure 4. Household adaptation measures.

\subsection{Factors Influencing the Amount of Implemented Adaptation Measures}

A linear regression model will be used for an evaluation of the factors influencing the amount of implemented adaptation measures. This will help identify which factors might serve as a positive drive for steps taken and which factors instead represent a barrier to adaptation as we have already described in the introductory section, particularly within the conceptual framework and literature review (Chapter 2). For the present purposes the characteristics of 1467 household members shall be made use of excluding those individuals who have the status of students [55]. Although one could formulate a model directly for individual households there would, consequently, be a need to aggregate the individual characteristics relating to education, income, commuting factors, etc. The estimated tendencies in decision-making concerning the number of implemented measures are not thereby affected.

The total number of adaptation measures (exterior and interior) which the households of individuals have consequently implemented since 1997 is taken as the dependent variable. All the explanatory variables were chosen at the start of the present analysis using the idea concerning the main factors which can influence individual behavior (see Figure 1). These factors represent experience with the intensity of flooding, insurance of the household against natural disasters, volume of damages as a consequence of experienced floods, subjective perception of preparedness for floods, preparedness of the municipality in which the individuals in question live, subjective perception of the risk of flood, number of children in the household and individual (socio-demographic) characteristics representing education, marital status, household income, commuting situation to work, etc. Subjective perceptions of preparedness for flooding were measured directly as ordinary variables determined by the answers of the respondents. The lowest value of one means that the subjective level of preparedness is excellent and the highest value of five means insufficient preparedness. A stepwise regression approach has been applied in order to determine the most influential factors. The variables were added to the model provided that the $F$ statistic $p$-value is below the level of significance (stated as 0.15 ) and were removed if and when the $p$-value exceeded the level of significance (stated as 0.15 ). The results 
remained stable in relation to the changes in the levels of significance. The parameter estimates of the final model with statistically significant variables are presented in Table 7.

Table 7. Factors influencing the number of adopted adaptation measures.

\begin{tabular}{ccc}
\hline & Coefficient Estimate & Standard Error \\
\hline Intercept & 0.01718 & 0.109 \\
nexp_year & $0.27105 * * *$ & 0.05923 \\
exp_int & $0.02351 * * *$ & 0.00549 \\
ins_before1 & $0.3994 * * *$ & 0.14786 \\
loss1_big & $0.55463 * * *$ & 0.10105 \\
loss2_big & $-0.86775 *$ & 0.48651 \\
ins2_ratio & $-0.02805 *$ & 0.01036 \\
educ3 & $0.27253 * * *$ & 0.13988 \\
married & 0.12096 & 0.07855 \\
occ_medium & 0.16168 & 0.10248 \\
empl_comm & $-0.17873 * *$ & 0.09045 \\
hh_child2 & $0.33001 * * *$ & 0.11043 \\
hh_child3 & $0.57537 * *$ & 0.22801 \\
risk_percep_2 & $0.25587 * * *$ & 0.09193 \\
risk_percep_3 & $0.77762 * * *$ & 0.11944 \\
flood_prep & $-0.047 * *$ & 0.02252 \\
sum_earning & $0.00000748 * * *$ & 0.00000191 \\
\hline
\end{tabular}

Notes: Number of observations 1467 , R-squared 0.2751 ; *** corresponds to the significance of the coefficient on the level of significance of $1 \%$; ** corresponds to the significance of the coefficient on the level of significance of $5 \%$; * corresponds to the significance of the coefficient on the level of significance of $10 \%$; Coefficients in the case of variables occ_medium and empl_comm were statistically significant up to the level of significance of $12 \%$.

There is an evident relationship between experiences with floods and the number of implemented adaptation measures from the results of the estimates of the linear regression model (illustrated in Table 7). The positive, statistically significant coefficient in the variable expressing the number of experiences with floods (nexp_year) indicates that people who have more experience with floods have a tendency to apply more adaptation measures. A similar positive relationship can be found in the case of variables expressing the intensity of the experience of floods (exp_int) and the experience of greater damages as a consequence of the first flood (specifically above fifty-thousand CZK). In contrast, respondents who repeatedly experienced floods with damages exceeding fifty-thousand CZK (variable loss2_big) have a tendency to implement a lower number of adaptation measures. This dependency is demonstrable, however, up to a $10 \%$ level of significance.

As regards insurance, the coefficient in the case of the variable expressing whether a given individual (household) was insured before the first floods (ins_before1) indicates that respondents insured before the first flood tended to adapt more measures. From the perspective of the influence of the proportion of damages covered by insurance, the proportion of damages covered is shown to be statistically significant only after the second floods (variable ins2_ratio). There is a tendency to take less adaptation measures in cases when the proportion of damages covered by insurance is higher. The 
explanation for this phenomenon may be that insurance represents a component of the strategy of adaptation to floods for households which have experience with floods.

A further finding is the fact that respondents with university education (i.e., at least a Bachelor's degree as expressed by variable educ3) tend to adopt more measures in comparison with those with a primary or secondary education level. Respondents with two (hh_child2) and three children (hh_child3), respectively, tend to adopt more adaptation measures than respondents with one child or no children. The effect of respondents with three and more children is also higher than those with two children.

The findings related to the perception of risk are unsurprising. Respondents who perceive that they are living in a low-risk area (variable risk_percep_2) tend to adopt more adaptation measures than those perceiving that they live in a no-risk area and respondents who perceive that they are living in a high-risk area (risk_percep_3) tend to adopt more adaptation measures than those perceiving that they live in a no-risk area. This effect is triple that of the effect of those who perceived they lived in a low-risk area. Similarly, households perceiving the flood preparedness of their houses and other properties as solid (variable flood_prep) tend to adopt more measures in comparison with pessimistic households. Higher household income (sum_earning) and employment in a field requiring a medium-qualified labor force (occ_medium) are also statistically significant factors leading to the adoption of a larger number of adaptation measures.

In contrast, a surprising finding is that employed and commuting respondents (variable empl_comm) tend to adopt less adaptation measures than retired or non-commuting respondents (basic category). The explanation for this effect may be the fact that both groups of inhabitants have more time to implement these measures by themselves, this being typical of Czech rural areas. Another reason may be the fact that both old-age pensioners and people who do not commute to work are both actually and psychologically more dependent on their existing home. Abandoning their existing dwelling may represent an essential problem for pensioners since the costs for rectification of the consequences of floods or the need for resettlement without the possibility of obtaining financial resources for another dwelling may present an insoluble situation. The fear of loss of their home may represent a frustration which is of a motivational character in terms of implementing long-term adaptation measures for inhabitants who do not commute and who are more fixed in terms of their dwelling.

\section{Results and Discussion}

An increasing frequency in the occurrence of floods in the investigated territory in the catchment basin of the Bečva River can be confirmed from the data obtained through our research; thus, the implementation of adaptation measures is increasing in importance. Our findings generally reveal that household adaptation is relatively low and needs to be improved. These findings are similar to those of Porter et al. [35], who also found a low level of long-term and costly adaptation measures applied by households.

A more detailed view of the years of the construction of the new houses indicates that houses in high-risk zones were constructed without a raised ground floor even immediately after 1997 (see Table 3). If a raised ground floor is to be considered the main indicator of the long-term adaptation strategy, within the framework of the adaptation measures, then the first hypothesis, namely that households 
facing more frequent flood damages adopt measures to protect their home and property more often, was not entirely confirmed in the case of this indicator. The reason may be the assumption on the part of the households that a flood event of such intensity would not be repeated within the foreseeable future, or due to insufficient resources in connection with increased costs for the construction of a home with a raised ground floor. A considerable role was also played, however, by modern trends in architecture and civil engineering, as well as the short memory in relation to the floods.

Table 3 makes it possible to determine that the average percentage share of houses with a raised ground floor increased in the period following the floods of 1997 from $70 \%$ (corresponding to the proportion of houses constructed before 1997) to 81\%. This finding is not surprising with regards to the intensity of the flooding of 1997. A substantial number of authors $[30,38,40]$ have emphasized the positive aspect of a raised ground floor of a house in combination with a technical basement without a cellar (elevated house) which effectively resolves the possibilities for residence if there is a certain probability of the flooding of the house as a consequence of a river bursting its banks. Surprisingly the increase occurred primarily in low and no-risk zones. This proportion actually decreased in the high-risk zone. The preference for the construction of houses at ground level can be interpreted with reference to the fact that priority for a low price is in the interests of the inhabitants of the given region (an elevated house means higher costs), or that a role is played here by modern trends, a lack of knowledge or short memories. A further explanation for this finding is the fear of on the part of respondents of the consequences of further climate extremes such as extreme rainfall which may be connected to the erosion of lands (soil creeping). This occurs within this region and its manifestations may also affect areas which for the purpose of this survey have been evaluated as no-risk areas since floods do not occur there.

The regressive analysis demonstrated interesting findings in the case of the adoption of further adaptation measures on the part of households. The most statistically significant were shown to be factors of experience with floods, damages caused by floods and perceptions of the potential risk of flood danger. As regards the characteristics of households, the strongest relationship was demonstrated in the area of the number of children, education, and also insurance.

Higher numbers of children within the household and a higher level of education specifically increase the probability that more adaptation measures will be implemented. One of the explanations for this may be the fact that educated people as a rule are more thorough in considering the consequences of their choices and above all the risks in connection therewith. A family with one or more children is more restricted in terms of flexible changes (resettlement) or changes on a large scale within the household (re-mediation of flood damages). The restrictions consist of both the dramatic impact on the everyday life of the family (e.g., the organization of commuting to school or work or even a change thereof, resettlement to another community, impact on the life of children, etc.) and primarily in the possibilities for financing extensive reconstruction or even a new house following severe flood damage to the house (practically every young family in the Czech Republic has at least one mortgage). These as well as an entire range of additional reasons may be the reason why educated people living in families with children invest more in a wider range of anti-flood measures, which-if they fulfill their purpose in the case of necessity — entail a far smaller impact on a range of aspects of family life. 
These findings partially correspond with those of Kreibich [39] who identified ownership of a house and household size (the number of residents and number of children living in a house) as the most significant factors with regard to motivation to adopt precautionary measures on a house. Perception of climate change and flood risk was less significant. She also demonstrated that flood experience is a strong motivation towards adaptation measures.

Our findings dealing with the role of perception correspond with that of Bichard and Kazmieszak [36] who discovered that younger people and those who are more aware of climate change and flood threats are more motivated to adopt adaptation measures.

A comparison with these results of previous studies such as for example Grothmann and Reusswig [48] demonstrated a strong correlation between experiences with floods and the implementation of measures, this also having been confirmed by our regressive analysis. Localization of a home in a zone of increased risk (including with regards to perception as demonstrated by our regressive model) entailed a higher number of implemented adaptation measures. Economic variables such as income were shown to be similarly significant.

The various spectra of adaptation measures include insurance and migration to safer locations as a further possibility of adaptation. Over the course of the research, only one case was determined involving a family who moved from an unsuitable and damaged house to the highest point in the municipality. The municipality provided the option of moving and certain financial compensations to three families, only one of which decided to move (this concerned a small family) while the other two (older inhabitants) declined this offer.

In connection with insurance, more adaptation measures were applied by households which were insured before their first experience of flooding. In contrast, respondents with a higher ratio of damage covered by insurance after the second flood tended to adopt fewer measures. One explanation for this phenomenon may be the fact that insurance is the component of a strategy of adaptation to floods for households which already have experiences with floods and they rely on the fact that any damage caused will be compensated by insurance.

An additional possible explanation is that the majority of households which were affected by the first large floods of 1997 primarily required investments for repairs and did not envisage a repeat of the catastrophic experience. Furthermore, the insurance benefit provided by the insurance companies was not particularly high. Repeated experience with flooding may mean, however, information that similar events might repeat themselves and as a result insurance is paid as a partial adaptation strategy.

The sum of the measures in the high and low-risk zones reached $73 \%$ in all of the cases, whereas the proportion of measures in the no-risk zone is lower, i.e., 27\% (see Table 8). This situation can be interpreted with reference to the fact that property owners in the low-risk zones speculate that the return on the investment in preventive and adaptation measures may be higher than the costs for remediation of damages following any applicable flooding. Additionally, a house on which adaptation measures have been implemented is easier (and cheaper) to insure than a house without such measures. This speculation may be reversed in the no-risk zone. 
Table 8. Number of households according to risk zone and the number of implemented adaptation measures.

\begin{tabular}{ccccc}
\hline Sum of Adaptation Measures & No-risk & Low-risk & High-risk & Low + High-risk \\
\hline 0 & 120 & 110 & 45 & 155 \\
1 & 29 & 80 & 35 & 115 \\
2 & 11 & 37 & 46 & 83 \\
3 & 2 & 17 & 20 & 37 \\
4 & 1 & 12 & 11 & 23 \\
5 & 0 & 5 & 5 & 10 \\
6 & 0 & 7 & 4 & 11 \\
7 & 0 & 1 & 7 & 8 \\
Sum & 163 & 269 & 173 & 442 \\
Average & 0.374233 & 1.215613 & 1.901734 & 1.484163 \\
Average (\%) & $5.35 \%$ & $17.37 \%$ & $27.17 \%$ & $21.20 \%$ \\
\hline
\end{tabular}

Note: Average is the average number of measures per one household within the framework of the given risk zone. Average (\%) is the average percentage of the maximum possible number of available measures adopted on average by one household within the given risk zone.

When a case study approach is selected, a wider generalization of the conclusions is always problematic. As stated by Miceli et al. [56], comparisons between our data and previous studies dealing with the same issue are possible but not simple due to the differences regarding the geographical context, different instruments and the type of risk considered. A further limiting factor for a generalization or comparison is the selection of different methods for the studies in question. The situation will also not be any different in relation to the theme of household adaptation to the consequences of floods. It is, however, possible to state that the results of the research have potential for comparison and generalization from the perspective of regions with similar parameters (geographical, demographic, climatological, economic, etc.).

\section{Conclusions}

The study demonstrated and confirmed the first hypothesis that households in the Bečva River basin face floods and flood damage more frequently than in the past and that the higher frequency of climate extremes in connection with ongoing climate change is already being seen in the adaptation strategies of households situated in the affected regions. Adaptation measures in the case of households comprise a combination of short-term (coping) and partially long-term (adaptation) measures. There remains, however, significant room for improvement in the sense of increasing the effectiveness of the protection of existing structures with regard to climate extremes within this region, or the direct provision of technologies suitable for the construction of new homes or the reconstruction of older houses located in the risk areas. It has been shown that the majority of the measures determined were not particularly effective or that the potential of the adaptation measures was not fully utilized.

We argue that despite the situation which households are facing involving an increased number of repeated flood events, they are already partially prepared for them (by means of a raised ground floor). Furthermore, the inhabitants of the affected regions endeavor in a certain manner, even if this is not entirely effective, to adapt to these new climatic trends by means of various adjustments within their 
home, to the house itself and on the surrounding plots of land. Out of the total amount of adaptation measures which households can implement, even in the high-risk zone, these do not exceed 30\% (see Table 8); thus, the adaptation potential is far from fully utilized. According to Kundzewicz [57], households adopt an accommodation strategy only partially and protection or retreat strategies were observed to only a small extent.

From the perspective of the second hypothesis, the following aspects were identified as the most statistically significant social, demographic and economic variables influencing the decision-making of household members dealing with adoption of adaptation measures: experience with floods, damage caused by floods, perceptions of potential flood risk, number of household residents, family size (number of children), education, and also insurance. Specifically, more children within the household and a higher level of education increase the probability that more adaptation measures will be implemented. In relation to insurance, additional adaptation measures are applied by households which are insured prior to their first experience of flooding. Respondents with a higher ratio of damages covered by insurance after the second flood tend to, in contrast, adopt fewer measures.

The study reveals that a large scale flood which has caused considerable damages in households does not necessarily lead in the sum total to the choice of long-term adaptation measures in high-risk zones (if the construction of houses with a raised ground floor following the large floods of 1997 is chosen as our criterion). In addition to modern trends in architecture, a role is, in all probability, played by increased acquisition costs, short-term cultural memory in relation to the natural dynamics of the river floodplain, and speculation that a similar large flood will not be repeated within the foreseeable future.

A more pronounced reaction in both interior and exterior measures can only be found in the period of several years following the large floods, with regard to both new construction and reconstruction works. A higher frequency of adaptation measures was surprisingly found in lower risk zones. It can be assumed that a role was played by fear of the unknown where in the case of inhabitants of high-risk zones the experience of a managed flood event paradoxically reduced the motivation to implement costly and extensive anti-flood measures along the lines of a raised ground floor. A role may also have been played, however, by the fact that the remediation of flood damages in households hit by large scale flooding financially exhausted their budgets to such an extent that they could not afford investments in anything other than short-term measures. Education and the number of children also play a role in the selection of the type of measures. A greater frequency of anti-flood measures was determined amongst both university educated families and families with two or more children indicating that the larger the number of children, the greater the number of adopted measures. Employment also plays a role. Inhabitants of a productive age who commute to work have less time to implement measures than, for example, pensioners, a fact which is reflected in the number of implemented measures.

With regard to ongoing climate change in connection with a considerable degree of insecurity and the increased frequency of climate extremes, as well as from the perspective of long-term adaptation, the most effective method would be to avoid both high and low-risk zones in the construction of houses. It is further argued, similarly to several other authors such as Porter et al. [35], Bichard and Krazmieczik [36], and Kreibich [39], that environmental education, an increase in people's awareness of feasible methods of adaptation and improved flood risk communication between municipalities and residents are needed. Further research has shown that economically sounder households are more 
capable of adopting adaptation measures, indicating that certain supported programs for less economically secure households are needed.

We have learned from the obtained findings and compiled the following recommendations for policy makers. From an administrative perspective, it is essential to prevent new development within the inundation zone (high-risk areas) and introduce an obligation to take into account adaptation measures (e.g., a raised ground floor) when granting permission for new construction in low-risk areas. Czech legislation currently forbids new house construction in the highest risk areas (up to Q20) and only recommends the building of higher house elevations in low-risk areas (up to Q100).

Managing further flood damage for the economically-insecure population can represent an essential problem for these households. There is a need for partial support from public authorities (either regional or central) in the form of various proactive subsidies and incentives leading to relocation from the most threatened regions, or the implementation of suitable adaptation methods, in connection with the increased probability of further flood events and the virtual zero migration from the affected areas (also caused by the low level of payments from insurance companies). There is a need to address specific types of adaptation measures of a larger scope on the level of municipalities according to the specific geomorphological, geographical, and hydrological conditions on a regional level.

The study significantly contributed to filling in gaps in observing the individual level of adaptation to climate change, specifically households and flood events in Central Europe. It also outlined possibilities for the realization of the considerable potential of households within other areas; for example, the most effective management of water sources, adaptation to water scarcity, and the occurrence of droughts, or the overall potential of the sustainability of households with regard to natural resources and environmental changes, including climate change. In order to make a comparison and a critical analysis of the attained results possible, it would be appropriate to conduct research on a similar theme in other additional countries using the same methodology, ideally in regions with comparable natural conditions. With regard to the region in which the research was conducted, Slovakia and the north-eastern region of Austria would appear to be the most suitable initial territory.

\section{Acknowledgments}

This study was co-financed by a project of the European Social Fund and the state budget of the Czech Republic (POST-UP II, CZ.1.07/2.3.00/30.0041). The results of the paper were presented and discussed in workshops of COST Action IS1101 "Climate Change and Migration: Knowledge, Law and Policy, and Theory" and COST Action IS1309 "Innovations in Climate Governance: Sources, Patterns and Effects (INOGOV)”. We would like to express our gratitude to the respondents who shared their personal information and the interviewers who patiently collected their answers. The data is confidential since it contains personal and sensitive information about the respondents and authors fully guarantee their absolute anonymity.

\section{Author Contributions}

Robert Stojanov led the research team, conceived and drafted the paper. Barbora Duží contributed to the research design, the theoretical framework, the methodology and the analysed data. Tomáš Daněk conceived the paper, contributed to the research design and finalised the paper. All of 
the above reviewed the related studies and collected data. Daniel Němec analysed and processed the data, and David Procházka was responsible for all the geographical inputs and outputs including maps. All the authors wrote, reviewed and commented on the manuscript. All the authors read and approved the final manuscript.

\section{Conflicts of Interest}

The authors declare no conflict of interest.

\section{References and Notes}

1. IPCC. Managing the Risks of Extreme Events and Disasters to Advance Climate Change Adaptation; A Special Report of Working Groups I and II of the Intergovernmental Panel on Climate Change; Field, C.B., Barros, V., Stocker, T.F., Qin, D., Dokken, D.J., Ebi, K.L., Mastrandrea, M.D., Mach, K.J., Plattner, G.-K., Allen, S.K., et al., Eds.; Cambridge University Press: Cambridge, UK; New York, NY, USA, 2012; p. 582.

2. Climate Change, Impacts and Vulnerability in Europe 2012; EEA Report No. 12; EEA: Copenhagen, Denmark, 2012; p. 300.

3. Wamsler, Ch.; Brink, E. Planning for Climatic Extremes and Variability: A Review of Swedish Municipalities’ Adaptation Responses. Sustainability 2014, 6, 1359-1385.

4. Plummer, R.; Baird, J. Adaptive Co-Management for Climate Change Adaptation: Consideration for the Barent Region. Sustainability 2013, 5, 629-642.

5. Reid, H.; Alam, M.; Berger, R.; Cannon, T.; Huq, S.; Milligan, A. (Eds.) Participatory Learning and Action: Community-Based Adaptation to Climate Change; International Institute for Environment and Development (IIED): London, UK, 2009; p. 221.

6. Brázdil, R.; Dobrovolny, P.; Kakos, V.; Kotyza, O. Historical and Recent Floods in the Czech Republic: Causes, Seasonality, Trends, Impacts. In Flood Risk Management: Hazards, Vulnerability and Mitigation Measures; NATO Science Series; Schanze, J., Zeman, E., Marsalek, J., Eds.; Springer: Berlin, Germany, 2006; Volume 67, pp. 247-259.

7. Alfieri, L.; Burek, P.; Feyen, L.; Forzieri, G. Global warming increases the frequency of river floods in Europe. Hydrol. Earth Syst. Sci. Discuss. 2015, 12, 1119-1152.

8. Hansen, J.; Satoa, M.; Ruedy, R. Perception of Climate Change. PNAS 2012, 109, E2415-E2423.

9. Coucou, D.; Rahmstorf, S. A decade of weather extremes. Nat. Clim. Chang. 2012, 2, 491-496.

10. Bradshaw, B.; Dolan, H.; Smith, B. Farm-level adaptation to climatic variability and change: Crop diversification in the Canadian prairies. Clim. Chang. 2002, 67, 119-141.

11. Codjoe, S.N.A.; Owusu, G. Climate change/variability and food systems: Evidence from Afram Plains, Ghana. Reg. Environ. Chang. 2011, 11, 753-765.

12. Kelman, I.; Mercer, J.; West, J. Combining different knowledges: Community-based climate change adaptation in small island developing states. Particip. Learn. Action Notes 2009, 60, 41-53.

13. McLeman, R.; Mayo, D.; Strebeck, E.; Smit, B. Drought adaptation in rural eastern Oklahoma in the 1930s: Lessons for climate change adaptation research. Mitig. Adapt. Strateg. Glob. Chang. 2008, 13, 379-400. 
14. Fincher, R.; Barnett, J.; Graham, S.; Hurlimann, A. Time stories: Making sense of futures in anticipation of sea-level rise. Geoforum 2014, 56, 201-210.

15. McLeman, R.; Smit, B. Migration as an adaptation to climate change. Clim. Chang. 2006, 76, 31-53.

16. Smit, B.; Burton, I.; Klein, R.J.T.; Wandel, J. An anatomy of adaptation to climate change and variability. Clim. Chang. 2000, 45, 223-251.

17. Adger, W.N.; Barnett, J.; Brown, K.; Marshall, N.; O’Brien, K. Cultural dimensions of climate change impacts and adaptation. Nat. Clim. Chang. 2013, 3, 112-117.

18. Fankhauser, S. The costs of adaptation. WIREs Clim. Chang. 2010, 1, 23-30.

19. Tompkins, E.L.; Eakin, H. Managing private and public adaptation to climate change. Glob. Environ. Chang. 2012, 22, 3-11.

20. Machar, I.; Drobilova, L. Ochrana Prirody a Krajiny v Ceske Republice; Palacky University: Olomouc, Czech Republic, 2012; Volume II, p. 853.

21. Heffernan, O. No going back. Nature 2012, 491, 659-661.

22. Lass, W.; Haas, A.; Hinkel, J.; Jaeger, C. Avoiding the Avoidable: Towards a European Heat Waves Risk Governance. Int. J. Disaster Risk Sci. 2011, 1, 1-14.

23. McCarthy, J.J.; Canziani, O.F.; Leary, N.A.; Dokken, D.J.; White, K.S. Climate Change 2001: Impacts, Adaptation, and Vulnerability. Contribution of Working Group II to the Third Assessment Report of the Intergovernmental Panel on Climate Change; Cambridge University Press: Cambridge, UK, 2001.

24. Kreibich, H.; Thieken, A.H.; Petrow, Th.; Müller, M.; Merz, B. Flood reduction of private households due to building precautionary measures: Lessons learned from the Elbe flood in August 2002. Nat. Hazard Earth Syst. Sci. 2005, 5, 117-126.

25. IPCC. Climate Change 2007: Synthesis Report. Contribution of Working Groups I, II and III to the Fourth Assessment Report of the Intergovernmental Panel on Climate Change; Core Writing Team, Pachauri, R.K., Reisinger, A., Eds.; IPCC: Geneva, Switzerland, 2007.

26. Reid, H.; Huq, S. Mainstreaming community-based adaptation into national and local planning. Clim. Dev. 2014, 6, 291-292.

27. Reid, H. Ecosystem- and community-based adaptation: Learning from community-based natural resource management. Clim. Dev. 2015, doi:10.1080/17565529.2015.1034233.

28. Van Aalsta, M.K.; Cannonb, T.; Burton, I. Community level adaptation to climate change: The potential role of participatory community risk assessment. Glob. Environ. Chang. 2008, 18, 165-179.

29. Mechler, R.; Kundzewicz, Z.W. Assesing adaptatin to extreme weather events in Europe-Editorial. Mitig. Adapt. Strateg. Glob. Chang. 2010, 15, 611-620.

30. Vaishar, A. Krajina, Lidé a Povodně v Povodí řky Moravy: Regionálně Geografická Studie; Regiograph: Brno, Czech Republic, 2002. (In Czech)

31. Etkin, D. Risk Transference and Related Trends: Driving Forces towards More Mega-Disasters. Environ. Hazards 1999, 1, 69-75.

32. Fordham, M. Participatory planning for flood mitigation: Models and approaches. Aust. J. Emerg. Manag. 1999, 13, 27-34. 
33. Vávra, J.; Lapka, M.; Cudlínová, E.; Líšková-Dvořáková, Z. Local perception of floods in the Czech Republic and recent changes in state flood management strategies. J. Flood Risk Manag. 2015, 15, doi:10.1111/jfr3.12156.

34. Klijn, F.; Kreibich, H.; de Moel, H.; Penning-Rowsell, E. Adaptive flood risk management planning based on a comprehensive flood risk conceptualisation. Mitig. Adapt. Strateg. Glob. Chang. 2015, 20, 845-864.

35. Porter, J.; Dessai, S.; Tompkins, E.L. What do we know about UK household adaptation to climate change? A systematic review. Clim. Chang. 2014, 127, 371-379, doi:10.1007/s10584-014-1252-7.

36. Bichard, E.; Kazmierczak, A. Are homeowners willing to adapt to and mitigate the effects of climate change? Clim. Chang. 2012, 112, 633-654.

37. Lane, S.N.; November, V.; Landström, C.; Whatmore, S. Explaining rapid transitions in the practice of flood risk management. Ann. Assoc. Am. Geogr. 2013, 103, 330-342.

38. Kreibich, H.; Seifert, I.; Thieken, A.H.; Lindquist, E.; Wagner, K.; Merz, B. Recent changes in flood preparedness of private households and business in Germany. Reg. Environ. Chang. 2011, 11, 59-71.

39. Kreibich, H. Do perception of climate change influence precautionary measures? Int. J. Clim. Chang. Strateg. Manag. 2011, 3, 189-199.

40. Botzen, W.J.W.; Aerts, J.C.J.H.; van den Bergh, J.C.J. Individual preferences for reducing flood risk to near zero through elevation. Mitig. Adapt. Strateg. Glob. Chang. 2013, 18, 229-244.

41. Schelfaut, K.; Pannemans, B.; van der Craats, I.; Krywkow, J.; Mysiak, J.; Cools, J. Bringing flood resilience into practice: The FREEMAN project. Environ. Sci. Policy 2011, 14, 825-833.

42. Duží, B.; Vikhrov, D.; Kelman, I.; Stojanov, R.; Jakubínský, J. Household flood risk reduction in the Czech Republic. Mitig. Adapt. Strateg. Glob. Chang. 2015, 20, 499-504.

43. Duží, B.; Vikhrov, D.; Kelman, I.; Stojanov, R.; Juřička, D. Household Measures for River Flood Risk Reduction in the Czech Republic. J. Flood Risk Manag. 2015, doi:10.1111/jfr3.12132.

44. Brázdil, R.; Řezníčková, L.; Valášek, H.; Havlíček, M.; Dobrovolný, P.; Soukalová, E.; Řehánek T.; Skokanová, H. Fluctuations of floods of the river Morava (Czech Republic) in the 1691-2009 period: Interactions of natural and anthropogenic factors. Hydrol. Sci. J. 2011, 56, 468-485.

45. Yiou, P.; Ribereau, P.; Naveau, P.; Nogaj, M.; Brázdil, R. Statistical analysis of floods in Bohemia (Czech Republic) since 1825. Hydrol. Sci. J. 2006, 51, 930-945.

46. Vikhrov, D.; Stojanov, R.; Duží, B.; Juřička, D. Commuting patterns of Czech households exposed to flood risk from the Becva river. Environ. Hazards 2014, 11, 58-72.

47. Stojanov, R.; Kelman, I.; Shen, S.; Duží, B.; Upadhyay, H.; Vikhrov, D.; Lingaraj, G.R.; Mishra, A. Contextualising Typologies of Environmentally Induced Population Movement. Disaster Prev. Manag. 2014, 23, 508-523.

48. Grothmann, T.; Reusswig, F. People at risk of flooding: Why some residents take precautionary action while others do not. Nat. Hazards 2006, 38, 101-120.

49. DIBAVOD—Digital Base of Water Management Data of Czech Republic. Available online: http://www.dibavod.cz/ (accessed on 17 July 2014). (In Czech) 
50. The entire region of research ranks amongst the mild to warm climatic regions within the framework of Central Europe, with an influence of cooler waves from the regions of the Moravian-Silesian Beskydy mountain range. This mountain range is distinguished by higher totals of average rainfalls, which in the areas of the peaks reach $1200 \mathrm{~mm} / \mathrm{year}$, with average temperatures on the ridges around $5{ }^{\circ} \mathrm{C}$. In the foothills the average temperature in the valleys is within the region of $8-9{ }^{\circ} \mathrm{C}$ and average rainfalls are $900 \mathrm{~mm} /$ year, in lower areas the average temperature is $9.8^{\circ} \mathrm{C}$ and rainfalls $599 \mathrm{~mm} /$ year.

51. Van Ree, C.C.D.F.; Van, M.A; Heilemann, K.; Morris, M.W.; Royet, P.; Zevenbergen, C. FloodProBE: Technologies for improved safety of the built environment in relation to flood events. Environ. Sci. Policy 2011, 14, 874-883.

52. For higher precision, all maps are shown in Křovák cartographic projection. The exception is the map of Europe, which is displayed in the standard World Geodetic System 1984.

53. On the basis of experiences from interviews with respondents, we presume an underestimation of the damages as a consequence of the longer time interval, inflation and a worse ability to remember the damages caused in the more distant past. Estimates of the damages are presented as stated by the respondents.

54. This ratio is confirmed also by the auxiliary probit model, which contributed to a higher robustness of the results and estimated the probability of the adoption of one of the types of adaptation measures depending on the characteristics of the individual households (incorporating all the available relevant variables such as experiences with floods and their intensity, the degree of risk of the zone in which their house is located, the predominant representation of age, education, total income etc.). The estimated limiting influence of ownership of a house with a raised ground floor increases the probability of implementing one of the adaptation measures by approx. $11 \%$ for the average household.

55. Students are not included because of: (i) incomes and their potential distortion; (ii) but mainly due to the potential distortion of information relating to commuting to work, because from the perspective of adaptation measures, there is no sense in considering commuting to study.

56. Miceli, R.; Sotgiu, I.; Settanni, M. Disaster preparedness and perception of flood risk: A study in an alpine valley in Italy. J. Environ. Psychol. 2008, 28, 164-173.

57. Kundzewicz, Z.W. Floods and Flood Protection: Business-as-Usual? IAHS Publishing: Oxford, UK, 2004; pp. 201-209. Available online: http://hydrologie.org/redbooks/a286/iahs_286_ 0201.pdf (accessed on 14 September 2014).

(C) 2015 by the authors; licensee MDPI, Basel, Switzerland. This article is an open access article distributed under the terms and conditions of the Creative Commons Attribution license (http://creativecommons.org/licenses/by/4.0/). 